\title{
A Convenient Method for the Preparation of 3-Deoxyhexosones and 3-Deoxypentosone.
}

Sir:

The 3-deoxyosones were proved as intermediates in the melanoidin formation of sugars by interaction with amino compounds ${ }^{1)}$, and a considerable amount of 3deoxy-glucosone was isolated as its 2,4-dinitrophenylosazone from soy and miso ${ }^{2)}$. Anet ${ }^{3)}$ prepared the two 3-deoxy-D-hexosones by degradation of di-D-fructose- (and di-D-tagatose-) glycine* in dilute aqueous solution at $\mathrm{pH} 5$, and, Machell and Richards ${ }^{4}$ prepared 3deoxy-D-glucosone by treatment of 3-O-benzylD-glucose with $0.05 \mathrm{~N}$ sodium hydroxide. The only possible 3-deoxypentosone in its free form, however, remained unknown. In the present communication, the preparation of the two 3-deoxy-D-hexosones and the 3-deoxyD-pentosone by a simpler method is reported.

D-Xylose was heated with an equimolar amount of $n$-butylamine in methanol with occasional stirring at $60 \sim 65^{\circ} \mathrm{C}$ for twenty minutes, cooled to room temperature and then an equimolar amount of acetic acid was added and warmed at $55^{\circ} \mathrm{C}$ for seven minutes. Decolorization with active carbon and decationization on a column of Dowex 50-X4 gave a mixture of 3-deoxypentosone, xylose and small amounts of impurities. Separation by chromatography on a cellulose column gave the pure 3-deoxy-D-pentosone (I) as colorless solid, $[\alpha]_{\mathrm{D}}^{20}-13.4^{\circ} \rightarrow-17.2^{\circ}(\mathrm{c}, 1.86$ in water $)$, Anal. Found: C, 45.40; H, 6.68. Calcd. for

\footnotetext{
* 1,1'-(Carboxymethylimino) -bis-[1-deoxy-D-fructose (and -D-tagatose j].

1) H. Kato, This Journal, 24, 1 (1960).

2) H. Kato, Y. Yamada, K. Izaka and Y. Sakurai, J. Agr. Chem. Soc. Japan, 35, 412 (1961).

3) E. F. L. J. Anet, J. Am. Chem. Soc., 82, 1502 (1960); E. F. L. J. Anet, Aust. J. Chem., 13, 396 (1960).

4) G. Machell and G. N. Richards, J. Chem. Soc., 1960, 1938.
}

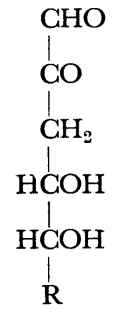

I : $\mathrm{R}=\mathrm{H}$, IIa \& IIb: $\mathrm{R}=\mathrm{CH}_{2} \mathrm{OH}$. (Open-chain form)

$\mathrm{C}_{5} \mathrm{H}_{8} \mathrm{O}_{4}: \mathrm{C}, 45.45 ; \mathrm{H}, 6.10 \%$. D-Glucose was similarly treated except the warming time at $55^{\circ} \mathrm{C}$ of two hours yielding 3-deoxy-D-glucosone (IIa, 3-deoxy-D-erythrohexosone) as white amorphous powder, $[\alpha]_{\mathrm{D}}^{17}-2.6^{\circ} \rightarrow+1.2^{\circ}(\mathrm{c}$, 6.6 in water), Anal. Found: C, 44.29; H, 5.89. Calcd. for $\mathrm{C}_{6} \mathrm{H}_{10} \mathrm{O}_{5}: \mathrm{C}, 44.44 ; \mathrm{H}, 6.22 \%$. In the case of $\mathrm{D}$-galactose, the warming time at $55^{\circ} \mathrm{C}$ was sixty minutes and 3-deoxy-D-galactosone (IIb, 3-deoxy-D-threohexosone) as white amorphous powder, $[\alpha]_{\mathrm{D}}^{18}+10^{\circ} \rightarrow+12.7^{\circ}$ (c, 5.2 in water), Anal. Found: C, 44.77; H, 6.49. Calcd. for $\mathrm{C}_{6} \mathrm{H}_{10} \mathrm{O}_{5}: \mathrm{C}, 44.44 ; \mathrm{H}, 6.22 \%$, was isolated.

Three 3-deoxyosones were extremely hygroscopic, but readily gave crystalline osazones by the reaction with substituted phenylhydrazines (Table I). These 3-deoxyosones showed the same color as parent sugars by aniline hydrogen phthalate, and the color reactions with 2-thiobarbituric acid in dilute phosphoric acid solution were positive. In addition, they revealed the activity in the Strecker degradation with $\alpha$-amino acid. 3Deoxypentosone was more unstable showing the stronger reactivity than 3-deoxyhexosones.

The author expresses his thanks to Prof. Yosito Sakurai for his guidance and also to 
Table I. Substituted Phenylosazones of 3-Deoxyosones

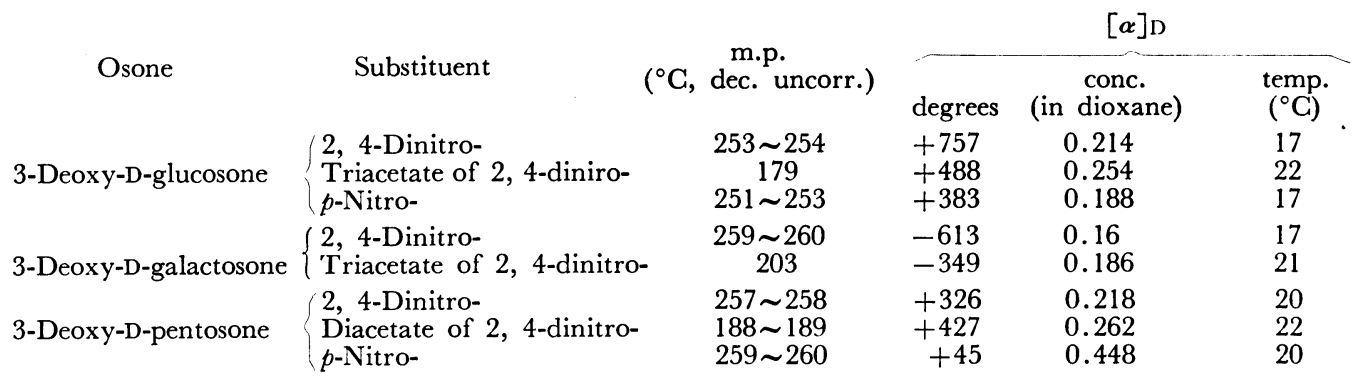

Ass. Prof. Masao Fujimaki for his encouragement. A part of this study was supported by a Grant in Aid for Scientific Research from the Ministry of Education.

Hiromichi Kato

Department of Agricultural Chemistry, Faculty of Agriculture, University of Tokyo.

Received June 20, 1961 